\title{
LXI. On finding the latitude by the altitudes of two stars
}

\section{Smith Esq.}

To cite this article: M. Smith Esq. (1824) LXI. On finding the latitude by the altitudes of two stars , Philosophical Magazine Series 1, 64:319, 351-353, DOI: $10.1080 / 14786442408644618$

To link to this article: http://dx.doi.org/10.1080/14786442408644618

曲 Published online: 27 Jul 2009.

Submit your article to this journal ๘

Џ Article views: 2

Q View related articles $\sqsubset$ 


\section{[ 351$]$}

LXI. On finding the Latitude by the Altitudes of two Stars.

By M. Sмuth, Esq.

To the Editors of the Philosophical Magazine and Journal.

Gentlemen,

I SEND you the following very simple and accurate method

1 of determining the latitude of any place in the northern hemispheres, by the altitudes of the two stars Aliath (or \& Ursa Majoris) and $\gamma$ Cassiopeice, taken at the same instant, without the hour of the night or any other data being required. The rule supposes the two stars to differ exactly twelve hours in right ascension; it will therefore be rigorously correct in the year 1831, and will not produce an error of a mile in the latitude for at least ten years before and after that period. The altitudes used must of course be the true altitudes of the stars, or those corrected for refraction and the dip of the horizon, and five places of decimals in the logarithms will be sufficiently accurate. I need not trouble you with the demonstration of the rule, as it is precisely analogous to that of reducing the lunar distance, and will therefore be understood by every astronomer.

The altitudes of the Stars Aliath and $y$ Cassiopeiæ given, to find the latitude of the place of observation:-

Rule.-Add together the two zenith distances and the constant arc $63^{\circ} 20^{\prime}$; take half the sum, from which subtract the zenith distance of Aliath and the constant arc $63^{\circ} 20^{\prime}$, noting the remainders.

Add together the sines of the two remainders, and the logarithm in the following table; take half the sum of these three logarithms, from which subtract the sine of half the difference between the declination and altitude of Aliath; the remainder is the tangent of an arc; the sine of this arc subtracted from the said half sum of the logarithms, leaves the sine of half the required co-latitude.

Table.

\begin{tabular}{|lll|l|l|l|}
\hline \multicolumn{3}{|c|}{ Years. } & \multicolumn{2}{c|}{ Eogarithm. } & \multicolumn{2}{c|}{ Decl. Aliath. } \\
\hline 1823 & 1824 & 1825 & $\mathbf{1 9 \cdot 7 8 5 9 2}$ & $56^{\circ}$ & $55^{\prime}$ \\
1826 & 1827 & 1828 & $19 \cdot 78612$ & 56 & 54 \\
1829 & 1830 & 1831 & $19 \cdot 78631$ & 56 & 53 \\
1832 & 1833 & 1834 & $19 \cdot 78650$ & 56 & 52 \\
1835 & 1836 & 1837 & $19 \cdot 78670$ & 56 & 51 \\
1838 & 1839 & 1840 & $19 \cdot 78689$ & 56 & 50 \\
1841 & 1842 & 1843 & $19 \cdot 78708$ & 56 & 49 \\
1844 & 1845 & 1846 & $19 \cdot 78728$ & 56 & 4.8 \\
\hline
\end{tabular}

Erample. 
$352 \mathrm{Mr}$. Smith onfinding the Latitude by the Altitudes of troo Stars.

Example. 1.

Given. The altitude of Aliath........ $=53^{\circ} 25^{\prime}$

The altitude of $\gamma$ Cassiopeiæ $=32 \quad 4.1$

Required. The latitude of the place.

Zen. dist. of Aliath...... $36^{\circ} 35^{\prime} \quad$ Decl. Aliath... $=\mathbf{5 6 ^ { \circ }} 55$

Zen. dist. of Cassiopeiæ $57 \quad 19 \quad$ Alt. Aliath ... $=5325$

Constant arc ............ $63 \quad 20$

2) 330

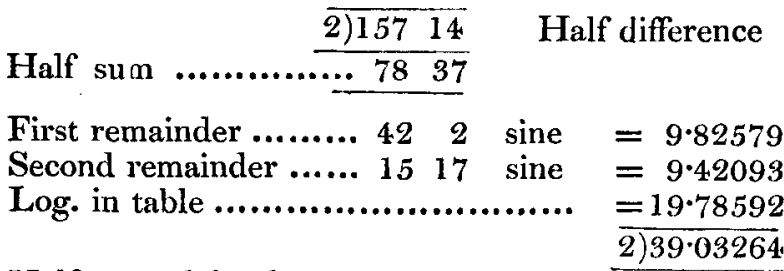

Half sum of the three logarithms ......... 19.51632

Half diff. decl. and alt. of Aliath $1^{\circ} 45^{\prime}$ sine $8 \cdot 48485$

Tangent of an arc .............. 84. $41^{\prime}=\overline{11.03147}$

Half sum of the three logarithms ... ... $=19 \cdot 51632$

Sine of the above arc............8 $84^{\circ} 41^{\prime}=9.99813$

Sine of half co-latitude ........ $19^{\circ} 15=9 \cdot 51819$

$$
\begin{aligned}
& \text { Co-latitude ... } \frac{2}{38 \quad 30} \\
& \text { Latitude...... 51 } 30 \text { north. }
\end{aligned}
$$

Example 2.

Given. The altitude of Aliath........ $42^{\circ} 20^{\prime}$

The altitude of $\gamma$ Cassiopeiæ $\quad 57 \quad 48$

Required. The latitude of the place.

Answer. Latitude $63^{\circ} 42^{\prime}$ north.

Note. - The constant $\operatorname{arc} 63^{\circ} 20^{\prime}$, is the distance between the two stars, and the logarithm in the table is the sum of the log. cosecant of that arc, and the log. cosine of the declination of Aliath.

It may be necessary to add, that the star $\Lambda$ liath is the first star in the tail of the Great Bear; and that $\gamma$ Cassiopeiæ is the centre star of five bright ones in that constellation, arranged in the form of the letter W. Their right ascensions and declinations for 1825, are as follows :

Aliath........ \& $12^{\mathrm{h}} 46^{\mathrm{m}} 17^{\mathrm{s}} \quad$ Decl. $56^{\circ} 54^{\prime} 42^{\prime \prime} \mathrm{N}$. $\gamma$ Cassiopeiæ $R \quad R \quad 0 \quad 46 \quad 12 \quad$ Decl. $59 \quad 46 \quad 3 \quad$ N.

1 remain, gentlemen,

Nov. 9, 1824,

Your most obedient servant,

M. Sinth.

P.S. 
P.S.-An answer toMr.SamuelCooper'squestions on the subject of mean solar time, having appeared in your last Number, I beg leave to observe, that your correspondent "Glosterian" is mistaken in the only instance in which he has given a direct answer to Mr. Cooper's queries. The sun's right ascension, as given in the Nautical Almanack, is expressed in sidereal. time, not in solar time. To prove this, it will suffice to observe, that at the instant of the sun entering Libra, his right ascension in the Nautical Almanack is 12 hours; whereas, had it been expressed in solar time, it would be only $11^{\mathrm{h}} 58^{\mathrm{m}} 2^{\mathrm{s}}$; the entire circle of the ecliptic passing the meridian in 24, hours. sidereal time, which is equal to $23^{\mathrm{h}} 56^{\mathrm{m}} 4^{\mathrm{s}}$ solar time.

LXII. Analyses of a Series of Papers on the Structure, Distribution, and Functions of the Nerves; by CharLes Beld, Esq.; which have appeared in some late Volumes of the Philosophical Transactions.

[Continued from p. 128.]

WR. BELL in pursuing the anatomy of those parts of the animal frame, which more immediately and distinctly exhibit the truth of the hypotheses with which he set out respecting the necessity of our viewing the nervous system, as divided into two grand classes; the one regulating and controlling the respiratory apparatus, and associating the actions of other parts therewith; the other proving the source of voluntary motion, and of sensibility; has endeavoured to illustrate that hypothesis still further, by the facts and observations which are furnished by the anatomy and physiology of the eye in particular.

The difficulties which must have presented themselves in making this attempt are, from the very compound nature and functions of this most beautiful organ, such as would be suffcient to deter most persons from seeking for illustration from it on any point; and it cannot but be regarded as an additional corroboration of the truth of this theory, when such a complicated system is seen to bear testimony to it in all its parts.

On the Motions of the Eye in illustration of the Uses of the Muscles and Nerves of the Orbit.-(Phil. Trans, 1823.)

The plan which Mr. Bell has adopted in order to confirm his doctrine of the nervous system by the anatomy and physiology of the eye is, first, to show the uses of the apparatus or frame-work, which is exterior to the eyeball; and then, in the

Vol. 64. No. 319. Nov. 1824. Y y second 